\title{
DEVELOPING A DATABASE FOR THERMALISM IN MOROCCO
}

\author{
Atid chaimaa \\ University ibn Tofail Kenitra, Morocco \\ Benmakhlouf Mohamed \\ Unversity Abdelmalek Esaadi Tetouan, Morocco \\ Chakiri Said \\ University ibn Tofail Kenitra, Morocco
}

\begin{abstract}
Morocco has significant geothermal potential. Currently, balneology is the main use (Atid et al.2019). Direct applications in the thermal field are very limited. Knowing that this source of energy can contribute to local development, we found it useful to create a database on thermalism linked to an information system we called "Navig Sources Morocco". This application will be available for the national and international professional and scientific communities without geographical limitations. It brings together all the information characterizing the hot springs. This information is easily and quickly accessible and can be a decision-making tool for any thermal application or project.
\end{abstract}

Keywords: Thermalism, balneology

Cite this Article: Atid chaimaa, Benmakhlouf Mohamed and Chakiri Said, Developing a Database for Thermalism in Morocco, International Journal of Civil Engineering and Technology, 11(04), 2020, pp.24-35

https://iaeme.com/Home/issue/IJCIET?Volume=11\&Issue $=4$

\section{INTRODUCTION}

The design and implementation of an information system incorporating information on hot springs, drilling and geothermal reservoirs can meet the needs of managers, private investors and professionals working in the field of water resources.

A multi-criterion analysis of the hot springs of northern Morocco has resulted in a classification of the hot springs and defines the prospects of their development by specifying their development axes. 
A study of the modules was conducted during the preliminary study. We captured the functional needs in terms of the actors we named profiles and their main features modeled in usage case diagrams.

After an evaluation of the most suitable application architecture and advanced expertise in computer science, a layered approach of different technologies and frameworks, was decided upon to develop the application namely in : J2EE and MVC 2, technologies facilitating a highly client-server platform for the development and execution of applications distributed across the internet.

The application, Navig Sources Maroc, will cater to a community of professional users interested in thermo-mineral hot springs from around the globe by offering interested parties easy access via the web to all the useful information about the thermo-mineral hot springs identified in this work with the help of satellite imaging technology.

In order to achieve a result that meets functional, technical and qualitative needs, we have developed our quality assurance plan (QAP). The full description of the QAPis presented in Appendix B.

The adequacy of the project with the selection of the development process can greatly affect the success of an IT project. Therefore, a poor choice of the development process can lead project failure.

We find that most of these methodologies require working with an iterative process, whether in terms of schedules, specifications or development.

If the iterative was selected it is because it reduces the complexity of achieving phases by working in successive and incremental approaches. It is then possible to quickly present validation elements to users. In addition, the iterative development process allows effective risk management by addressing difficult points from the first iterations.

The choice of software technology, and application architecture of our application is one of the most critical decisions of our project given the high degree of its technical complexity.

Since the 2TUP software development methodology allows us to ensure the itierative process is respected using our object oriented client server technologies selected throughout the entire development process.

The 2TUP proposes a Y-shaped development cycle that separates the technical aspects from the functional aspects. Illustrated in Figure 1, the Y-shaped process revolves around three phases:

1. a technical branch,

2. a functional branch

3. a phase of implementation.

Project planning is a very important step in ensuring the smooth running of the project throughout the phases of the development cycle.

Based on the meetings we had, we were able to identify the following key steps: Preliminary Study, Detailed Study, Architectural Study, Implementation and Implementation.

\section{FUNCTIONAL STUDY}

The functional analysis of the project helped us to identify the main components in the system and to break it down into several functional modules, namely:

1. Source management.

2. User management. 


\subsection{Source management}

It is essential to approach the study of hot springs while referring to their geological and structural context, since the nature of the thermal waters is linked to those of the lands crossed. Most studies of thermals define the nature of the water, while the nature of the terrain and the geology from which they spring is not mentioned, and in particular the associated underground structures.

Studying hot springs through chemical analyses can give us an idea of the nature and chemical composition of the waters in these springs. The contribution of the isotopic analyses gives us further information on the origin of the waters, the recharge altitude of the water resource and its age.

But all this information gives us only hypotheses about the water circuit of a hot spring. This is why understanding the physcial characteristics of the waters that emerge from these environments is essential. To know this environment, geological, structural and geophysical studies of the areas of emergence can complete the geochemical and isotopic studies to understand the water circuit from their underground aquifer orignis until their emergence across the various geophysical barriers.

To this end, a study of the structural control of hot springs in parallel with the hydrogeochemical study was carried out by El Morabiti Karim (2000) and Benmakhlouf Mohamed (2001).

The study looked at 22 hot springs (Table 1 and fig.1); in the four spa areas: The Rifaine South Rides, Saiss Basin, Eastern Rif and Eastern Morocco.

Table 1: The main hot springs of northern Morocco studied

\begin{tabular}{|c|c|c|c|c|c|c|}
\hline $\mathrm{N}^{\circ}$ & Nom & Carte $1 / 50000$ & Latitude & Longitude & Altitude(m) & Z.Thermale \\
\hline 1 & El Hamma-Outita & El Kansera & $34^{\circ} 07^{\prime} 59^{\prime \prime}$ & $05^{\circ} 50^{\prime} 20^{\prime \prime}$ & 120 & $\mathrm{~A}$ \\
\hline 2 & Ain Boudraa & Sidi kacem & $34^{\circ} 12^{\prime} 14^{\prime \prime}$ & $05^{\circ} 41^{\prime} 53^{\prime \prime}$ & 185 & A \\
\hline 3 & Bab Tiouka & Sidi kacem & $34^{\circ} 14^{\prime} 13^{\prime \prime}$ & $05^{\circ} 40^{\prime} 01^{\prime \prime}$ & 075 & $\mathrm{~A}$ \\
\hline 4 & My Idriss & Sidi kacem & $34^{\circ} 03^{\prime} 00^{\prime \prime}$ & $05^{\circ} 30^{\prime} 22^{\prime \prime}$ & 540 & A \\
\hline 5 & Ain Zegota & Sidi kacem & $34^{\circ} 09^{\prime} 02^{\prime \prime}$ & $05^{\circ} 31^{\prime} 23^{\prime \prime}$ & 270 & A \\
\hline 6 & Ain Teder & Beni Ammar & $34^{\circ} 06^{\prime} 40^{\prime \prime}$ & $05^{\circ} 26^{\prime} 20^{\prime \prime}$ & 360 & A \\
\hline 7 & Ain Ansar & Beni Ammar & $34^{\circ} 06^{\prime} 29^{\prime \prime}$ & $05^{\circ} 25^{\prime} 40^{\prime \prime}$ & 350 & $\mathrm{~A}$ \\
\hline 8 & Souk Tlat & Beni Ammar & $34^{\circ} 03^{\prime} 58^{\prime \prime}$ & $05^{\circ} 21^{\prime} 32^{\prime \prime}$ & 230 & $\mathrm{~A}$ \\
\hline 9 & Ain Tratt & Fes Ouest & $34^{\circ} 04^{\prime} 55^{\prime \prime}$ & $05^{\circ} 02^{\prime} 13^{\prime \prime}$ & 540 & A \\
\hline 10 & Hamma Zalagh & Fes Est & $34^{\circ} 07^{\prime} 34^{\prime \prime}$ & $04^{\circ} 54^{\prime} 38^{\prime \prime}$ & 510 & A \\
\hline 11 & My.Yaacoub & Fes Ouest & $34^{\circ} 04^{\prime} 55^{\prime \prime}$ & $05^{\circ} 10^{\prime} 55^{\prime \prime}$ & 375 & $\mathrm{~B}$ \\
\hline 12 & Ain Allah & Fes Ouest & $34^{\circ} 02^{\prime} 24^{\prime \prime}$ & $05^{\circ} 08^{\prime} 10^{\prime \prime}$ & 383 & $\mathrm{~B}$ \\
\hline 13 & Chafia Skhouna & Beni Ammar & $34^{\circ} 00^{\prime} 00^{\prime \prime}$ & $05^{\circ} 18^{\prime} 14^{\prime \prime}$ & 320 & B \\
\hline 14 & Ait Yekkou & Meknès & $33^{\circ} 50^{\prime} 00^{\prime \prime}$ & $05^{\circ} 37^{\prime} 53^{\prime \prime}$ & 540 & $\mathrm{~B}$ \\
\hline 15 & Sidi Harazem & Fes Est & $34^{\circ} 00^{\prime} 00^{\prime \prime}$ & $04^{\circ} 42^{\prime} 00^{\prime \prime}$ & 262 & $\mathrm{~B}$ \\
\hline 16 & Ain Skhinate & Fes Est & $34^{\circ} 02^{\prime} 10^{\prime \prime}$ & $04^{\circ} 51^{\prime} 40^{\prime \prime}$ & 280 & $\mathrm{~B}$ \\
\hline 17 & Ain Hamra & Aknoul & $34^{\circ} 44^{\prime} 00^{\prime \prime}$ & $03^{\circ} 55^{\prime} 00^{\prime \prime}$ & 1200 & $\mathrm{C}$ \\
\hline 18 & Ain Chifa & Midar & $34^{\circ} 54^{\prime} 07^{\prime}$ & $03^{\circ} 36^{\prime} 36^{\prime \prime}$ & 505 & $\mathrm{C}$ \\
\hline 19 & Ain Haddou & Zeghanghane & $35^{\circ} 08^{\prime} 25^{\prime \prime}$ & $03^{\circ} 05^{\prime} 24^{\prime \prime}$ & 150 & $\mathrm{C}$ \\
\hline 20 & Ain Hammam & Zeghanghane & $35^{\circ} 10^{\prime} 08^{\prime \prime}$ & $03^{\circ} 11^{\prime} 13^{\prime \prime}$ & 056 & $\mathrm{C}$ \\
\hline 21 & Ain Goutitir & Guercif & $34^{\circ} 21^{\prime} 07^{\prime \prime}$ & $03^{\circ} 03^{\prime} 32^{\prime \prime}$ & 380 & $\mathrm{D}$ \\
\hline 22 & Bou Rached & Bou Rached & $33^{\circ} 51^{\prime} 47^{\prime \prime}$ & $03^{\circ} 35^{\prime} 07^{\prime \prime}$ & 900 & $\mathrm{D}$ \\
\hline
\end{tabular}




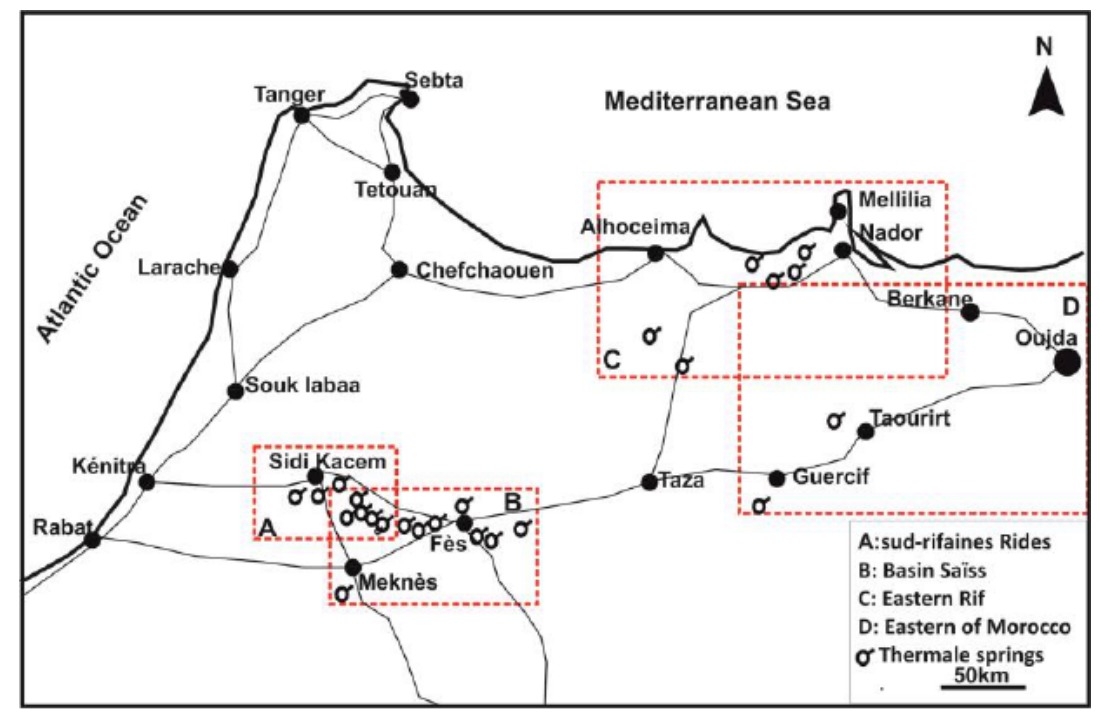

Figure 1. Location of thermo-mineral hot springs studied in this work

The hot springs studied in this work, are spread over the main geological areas of northern Morocco (Fig.2): The Rif, and more particularly along its overlapping front on the fore country and eastern Morocco, central Morocco.

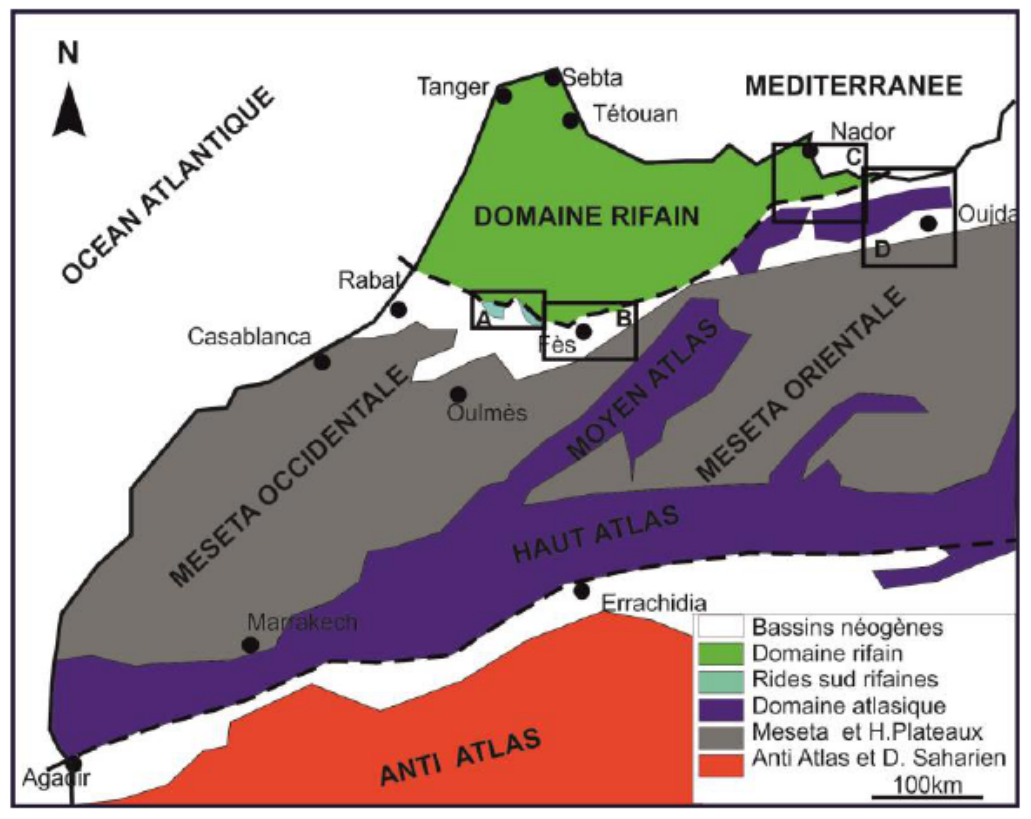

Figure.2: the main geological areas of northern Morocco

The management of thermo-mineral hot springs is done according to the following functional components: (Figure 3) 


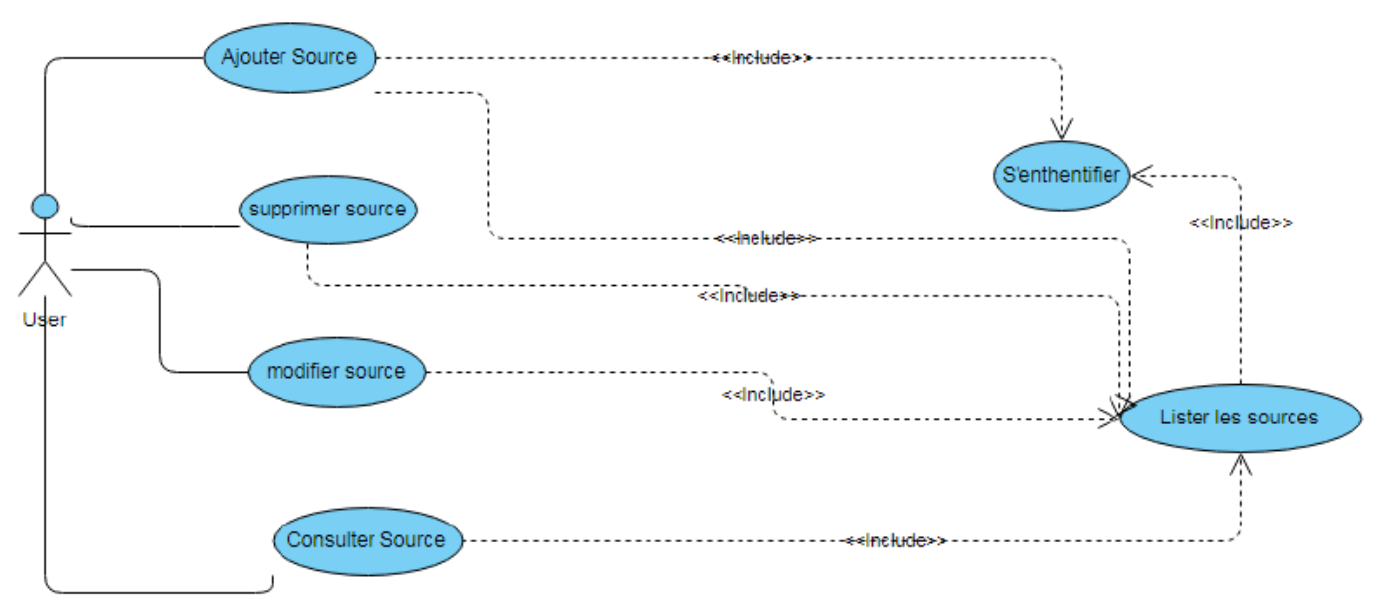

Figure 3. Source Management Use Case Chart thermo-mineral

1. Add a thermo-mineral source.

2. Change the parameters of a thermo-mineral source.

3. Remove a thermo-mineral source.

4. Consult a thermo-mineral source.

5. List thermo-mineral hot springs.

6. The authenticated user can access all components and functions

\subsection{User management.}

Each user in the system is a profile that can factor in multiple people with the same rights. The following context diagram summarizes the different users in the system and gives examples of functions that actors can exchange with the system.

The unidentified User profile can create an account on the platform and wait 48 hours to access the application. The UML use case diagram below (Figure 4) summarizes the features of the user management module cited above.

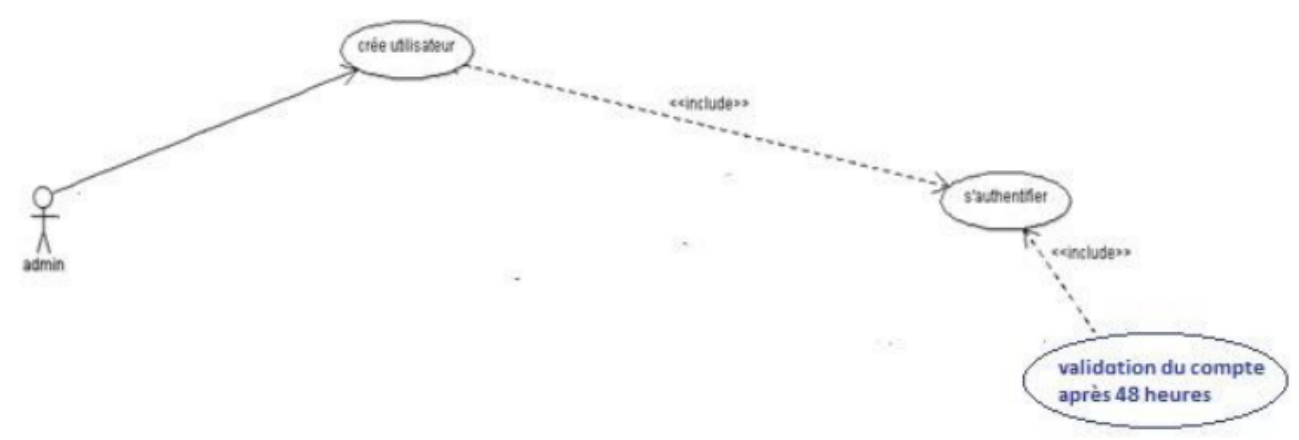

Figure.4: User Management Use Case Diagram 


\section{TECHNICAL STUDY}

We will present in paragraph the results of our technical study whose objective is to decide an application architecture consistent with our needs.

\subsection{Application Architecture}

Among the different ways of structuring architecture, the best adapted and mastered in computer science for distributed applications is the layered approach.

A layer is a logical and horizontal division of a system that provides a particular abstraction of the system to the upper layers. Each layer has specific responsibilities.

Such architecture offers the following advantages:

-Data management and business logic can be independent of the type of interface: The logic of the application and its data can be used by a separate interface.

-During the completion of the business layer, one can focus on the logic of application and the integrity of the data, without worrying about the presentation, and maintenance becomes easier.

-The presentation layer does not directly access the data, the configuration of data access is only done on the server where the data layer resides.

-If the business or data layer is changed, there is no modification to be done on the client interface.

The application has been broken down into 5 fundamental layers (Figure 5)

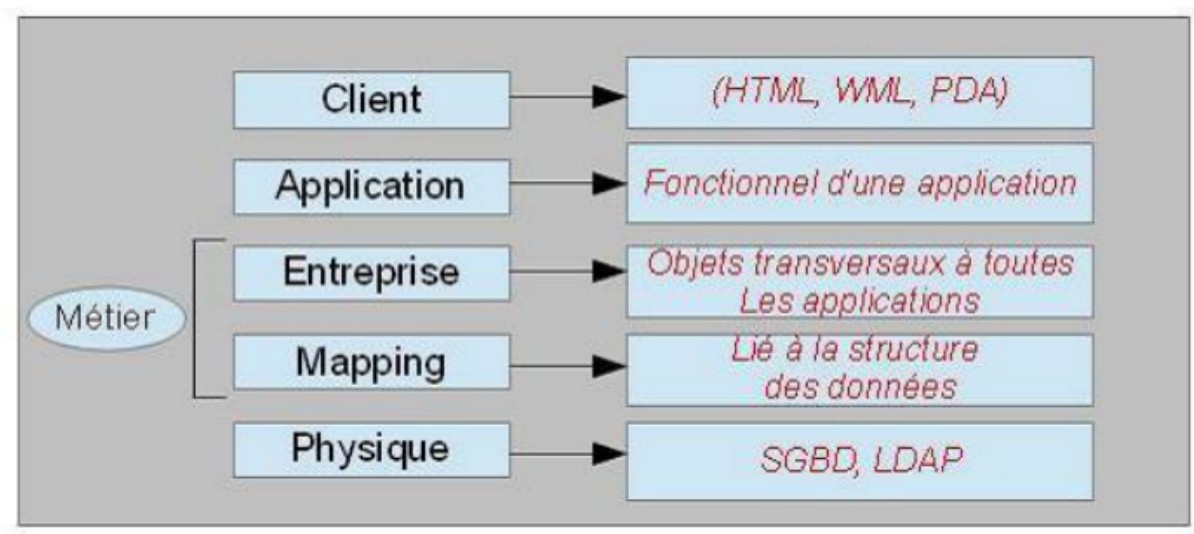

Figure 5. Software architecture

- Client layer.

- Application Layer.

- Business layer.

- Mapping Layer.

- Physical layer.

The five-tier architecture proposes to isolate the graphical interface in the client layer, the functionality in the Application layer, the business-to-business layer, the object/relational persistence in the Mapping layer, and the data in the physical layer. 


\subsection{Technology and Technical Frameworks:}

In this chapter, we presented the most adapted and mastered application architecture in computing is the layered approach and the different technologies and frameworks we used to make the application, which are:

J2EE which is the most suitable server-oriented platform for the development and execution of distributed applications. It is made up of two essential parts:

1. A set of specifications for an infrastructure in which components written in Java run: such an environment is called an application server.

2. A set of APIs that can be obtained and used separately. To be used, some require implementation from a third-party vendor.

Using J2EE to develop and execute an application has several advantages:

An application architecture based on components that allows a division of the application and thus a separation of roles during development.

The ability to interface with the existing information system through many APIs: JDBC, JNDI, JMS, JCA .

The freedom to choose the development tools and application servers used whether they are paid or open source.

J2EE allows great flexibility in the choice of application architecture by combining the different components. This choice depends on the needs of the application but also on the skills in the various API of J2EE. The architecture of an application is ideally divided into at least three-thirds:

1. The client component: this is the part that allows dialogue with the user. It can consist of a standalone application, a web application or applets.

2. The business component: it is the part that encapsulates the treatments (in EJB or JavaBeans)

3. The data component: it is the part that stores the data

-Spring is an opensource framework for building and defining the infrastructure of a JAVA application, which facilitates the development and testing of.

- Hibernate is a persistence framework used to manage the persistence of java objects in a database, it can be used in a web development or a heavy customer development. Hibernate can use SQL as it can use its own HQL query language (Hibernate Query Language).

- Apache Tomcat web server is the Java application server for the Apache Foundation's Jakarta project. This free server, licensed Apache allows to run web applications developed with Java technologies (Servlets, JSP ...).

- SGBD mySQL is a database management system.

The next chapter will focus on the next phase, which is the design phase.

\section{CONCEPTUAL STUDY}

The design stage is part of the 3rd major phase of the $\mathrm{Y}$ development process: the completion phase. Its objective is to take up the analysis model and render it in a more refined way to produce diagrams of application communication and classes.

For our project, we opted for UML (Unified Modeling Language) which proposes a standard design methodology for language and graphic notation for the creation of diagrams that allow to represent a system according to different complementary views. 


\subsection{Design Patterns:}

The use of good practice is essential to have an application that perfectly meets the intended user requirements. The main design patterns we've used at the application level to overcome recurring problems are:

-Singleton: whose purpose is to restrict the instantiation of a class to a single object.

-MVC 2: is an architecture and design method that organizes the human-machine interface (HMI) of a software application.

This paradigm divides the HMI into a model (data model), a view (presentation, user interface) and a controller (control logic, event management, synchronization), each with a specific role in the interface.

-DAO: it helps to isolate the way data is stored at the level of business objects. Thus, changing the storage mode does not call into question the rest of the application.

-Factory: it allows to instantiate objects whose type is derived from an abstract type.

Next, we will focus on the Design Pattern, namely the MVC2 given its great use in the project.

The MVC (Model View Controller, Figure 6) model is a Design Patterns in the "Structural Patterns" category. It's simple and at the same time very useful, it essentially allows you to design an application using the following three levels:

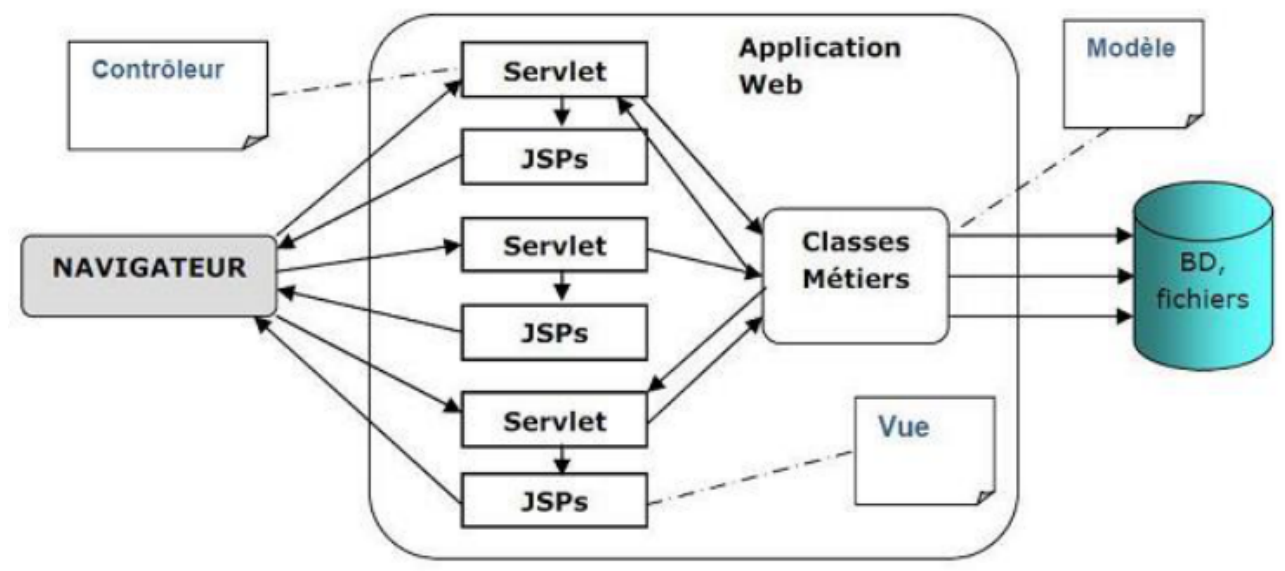

Figure 6. Modele MVC2

- Model: This is the core of the application. It maintains the state and data that the application represents. When significant changes appear in the model, the views will also be changed.

- Controller: It defines the behavior of the application and manages the interaction with the user. It uses the component model to respond to user queries.

-View: the user interface that is the visual representation of the "model."

This architecture, which separates control from user actions, the business layer and the presentation layer, facilitates the development and maintenance of an application. Despite this contribution, it has a major drawback: the multiplication of entry points (JSP and servlet pages) in the application. The implementation of services such as security, internationalization, or personalization then becomes complex with this architecture. The MVC2 model offers to overcome this disadvantage by using a single-entry point for each 
application. For example, an application contains a single front controller in the form of a single input servlet.

\subsection{Module validation process}

On a general level, a development project is divided into phases. A first phase allows us to decide on the choice of solution with a study of the existing and the target solutions.

Thus all the target solutions address only part of the project, and features are not covered, so functional gaps should be highlighted. These discrepancies will lead to specific developments to be undertaken.

To do this we decided to divide the process into four phases (Figure 7):

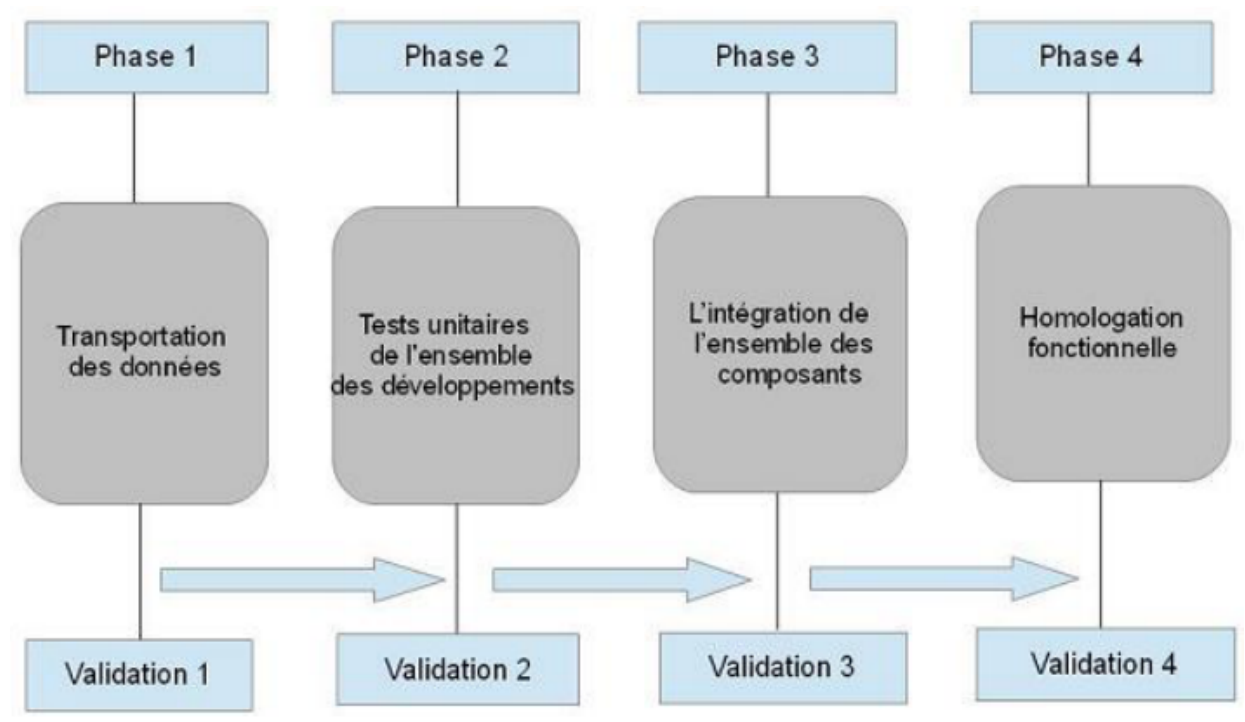

Figure 7 Phases of migration

1. Data transport phase.

2. Phase of unit tests of the various developments.

3. Integration phase of all components.

4. Approval phase

\section{IMPLEMENTATION}

After deepening our functional study of the system and detailing the conceptual study, we began the implementation phase by making prototypes that we validated in meetings with the end users of our system. Then we started the business part by implementing the application architecture that we had established at the technical study stage.

In this section, we present our application architecture and describe a few web based pages of the application.

\subsection{Implementation of the system architecture}

From the software architecture and the choice of working tools presented in the technical study chapter, we were able to set up the application architecture of the system.

The implementation of this architecture is the result of the implementation design phase. The application architecture has the different application layers of the system and combines each layer with the right execution tool. 
In order to master the development of the system, the application architecture of the system has been broken down into 4 layers (Figure 8):

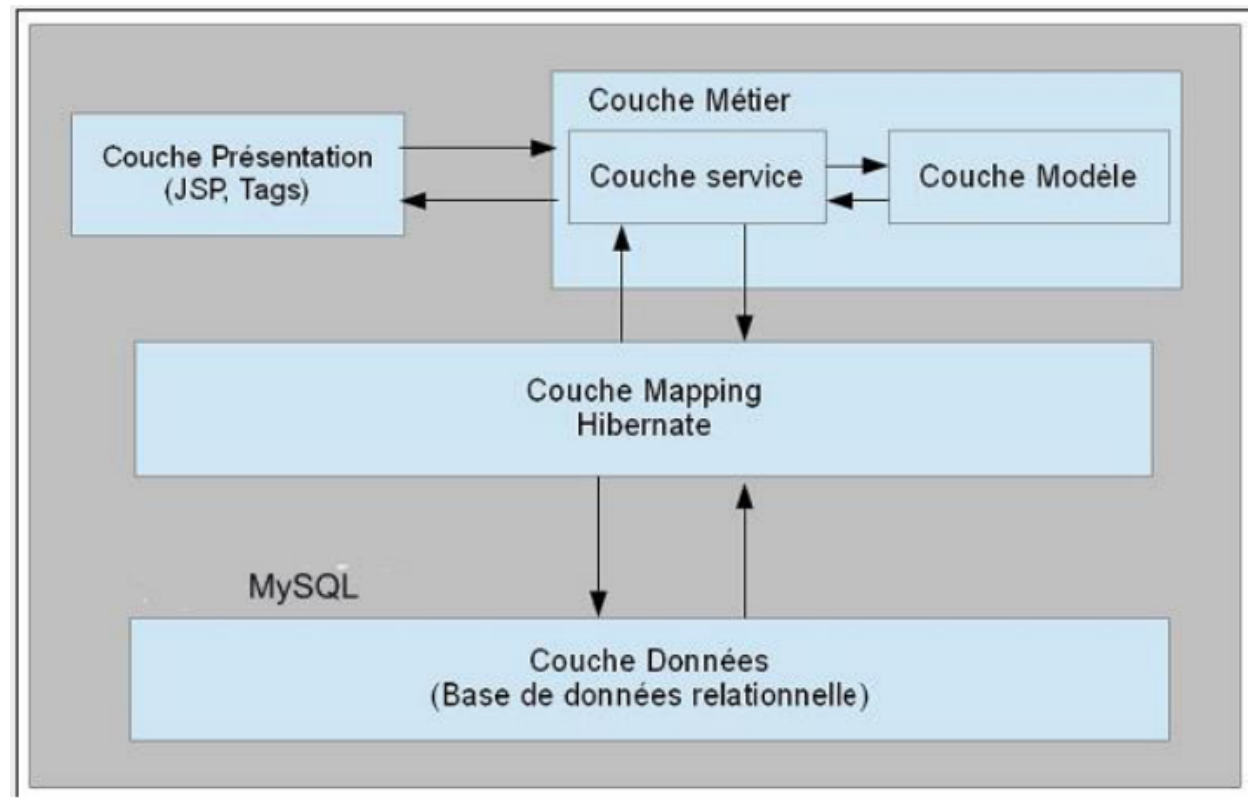

Figure 8. System application architecture

- Presentation layer.

- Business layer.

- Mapping layer.

- Data layer.

\subsection{Application management process (Navig Source Maroc):}

It is a satellite-connected application that allows the user to navigate freely in the region of Morocco by discovering the searchable database of all the thermo-mineral hot springs identified in this work.

\subsubsection{Geographic map of hot springs}

Figure 9a's map shows a satellite image of Morocco showing the various thermo-mineral hot springs identified and represented by the green pins.

Figure $9 \mathrm{~b}$ shows us the usefulness of the Zoom in mode, which allows us to geolocate thermo-mineral hot springs by revealing important details such as access routes, nearby settlements and general topography. 


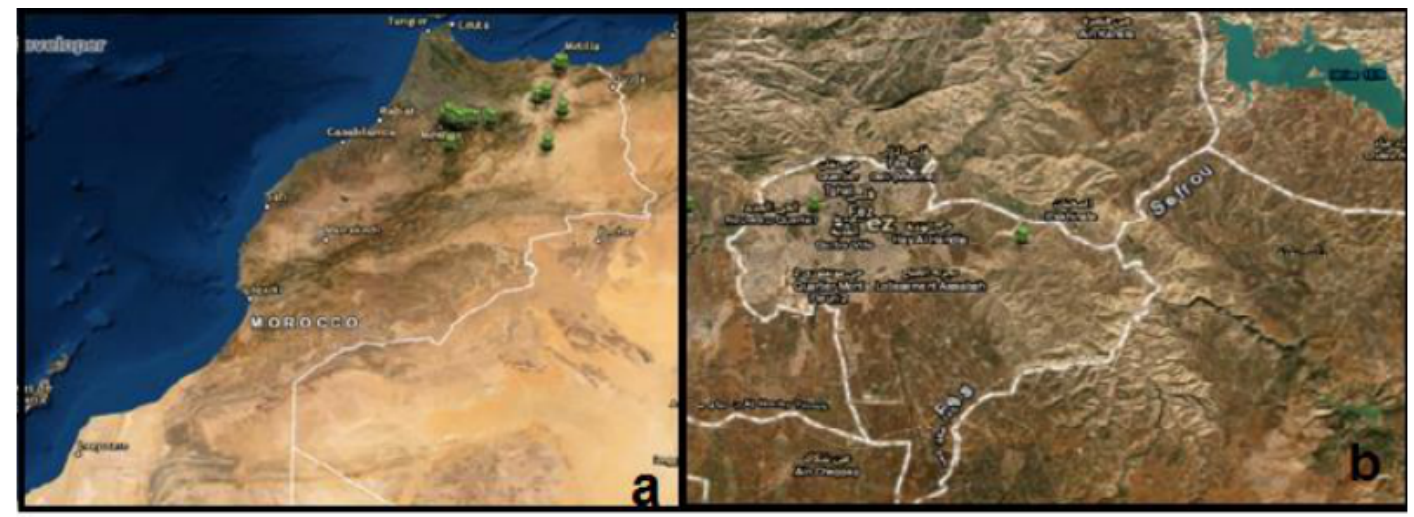

Figure.9: Geographic map of hot springs

\subsubsection{Example of a hot spring information sheet}

By clicking on a pin, several layers of information are presented to the user.. For this example of a hot spring, the navigable interface reveals the full hot spring data and provides another Zoom in function (Figure 10 a).
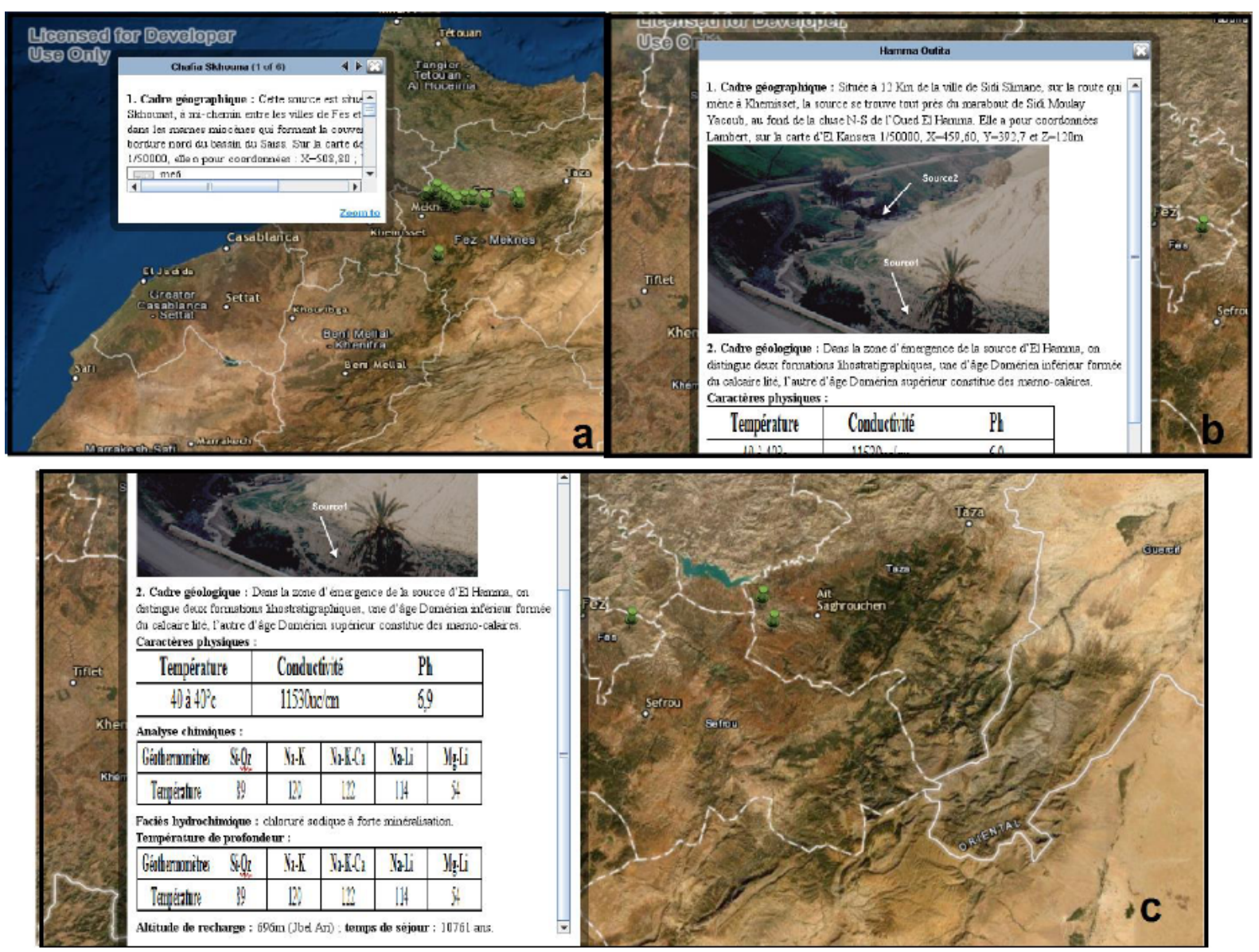

Figure.10: Hot Spring fact sheets

With zoom-in activation, the interface displays geographic information with a site image, plus geological data, and a table of physical characteristics for the thermo-mineral hot spring (Figure 10 b). 
With the activation of Zoom-in mode, the interface displays information on: Physical features, chemical analysis, hydro-chemical facies, residence time of the geothermal water, circulation depth, elevation and temperature of the recharge area concerning the source of El Hamma Outita.

This application, Navig Sources Maroc, allows interested parties to easily access via the web, with the help of satellite imaging technology, this powerful database application and search through all the useful information about the thermo-mineral hot springs identified in this work.

\section{CONCLUSION}

Natural mineral waters, whether used for thermal recreation or drinking water, are, by definition, underground waters, naturally well protected and bacteriologically healthy. These are meteoric waters that, from one or more feeding areas, use underground circuits, sometimes very deep, before reappearing during the day in natural resurgences or in artificial catchments such as wells or Drilling. The duration of this underground route corresponds to the age of the water, usually estimated in decades and sometimes in centuries.

The notion of natural protection of groundwater, especially mineral waters, unanimously recognized and affirmed by the scientific world for several decades, is an indisputable reality as long as all the hydromineral characteristics of the system remained undisturbed.

The design and implementation of an information system incorporating all the most important characteristics of hot springs, drilling and geothermal reservoirs can meet the needs of water resource managers, private investors and professionals working in the field of water resources.

Throughout this work, we carried out a multi-criterion analysis (chemical facies, sustainability, productivity, vulnerability, etc.) which will result in a classification of the hot springs and enable end users, such as policy makers and private sector developers, the decision tools to balance the protection of such a valuable resources while opening up opportunities for economic and social development.

While building Navig Source Morocco, we have deepened our functional study of the modules found in the preliminary study. Thus, we captured the functional needs in terms of actors that have been named profiles and main features modeled in use case diagrams using a Universal Modeling Language.

We presented the most suitable application architecture derived from our in-depth knowledge of computer science for the layered approach using different technologies and frameworks, including J2EE, server-oriented technology for distributed applications on the internet.

We also presented a conceptual view of the system to be realized, including the choice of the chosen design pattern, including the MVC 2, given its wide use and adaptability to meet the afore-mentioned challenges of this development.

This Web application Navig Sources Maroc offers simple and fast navigation for any user with average computer skills. It will foster a community of professional users interested in thermo-mineral hot springs without geographical limitation. The system features offer unlimited possibilities for managing hot spring data while creating new knowledge sharing possibilities in this field from experts around the world. 